\title{
EDITORIAL
}

\section{Can we engage learners through Web 2.0 and mobile devices?}

This issue brings together five rather diverse papers focusing on the use of mobile and Web 2.0 technologies in an effort to engage learners. Two of the papers deal with messaging or response systems used by students in higher education, two papers deal with the use of (mobile) social media for professional development of teachers, and the final paper builds a theoretical model for Web 2.0-based workplace learning.

Sharon Lauricella and Robin Kay (2013) report on the use of text messages (SMS) and instant messages (MSN Messenger) at a Faculty of Social Sciences and Humanities at a small Canadian University. The paper focuses on student attitudes towards the use of messaging as an extra opportunity for teacher-student and studentstudent communication outside of the classroom. Students in three instructor-led courses were offered text and instant messaging as extra communication channels with their instructor aside traditional face-to-face and e-mail contacts. The purpose of this communication was to ask questions or to obtain information relative to the course. The research questions addressed in the paper are: (1) How comfortable are students with using mobile phones or instant messaging? (2) How often do students use mobile phones and instant messaging to communicate with their instructor or peers? (3) How do students rate the usefulness of mobile phones and instant messaging for communicating with their instructor or peers for academic purposes? (4) Why do students use mobile phones or instant messaging to communicate with their instructor and peers? (5) Are there differences between text messaging with mobile phones and instant messaging? (6) Are there differences between the use of mobile phones with instructors vs. peers?

The study is based on the data obtained from the responses of 75 students to an online post-course survey. The results showed that when students were given the opportunity, they used text messaging via mobile phones with their instructor, though with less frequency than they did with their peers. Benefits of exchanging text messages with the instructor included resolving urgent issues, dealing with administrative questions and receiving a quick response to academic questions. Among peers, text messaging was used for arranging group meetings or giving/receiving academic assistance. Text messaging is therefore an instant, convenient and pervasive means by which both students and faculty can resolve and address issues requiring immediate attention. Instant messaging, however, was perceived as less 'instant' than text messaging, and while it was used among peers for organising group activities, sharing files and discussing academic issues, it was less helpful when used with the instructor. This study suggests that given the near ubiquity of mobile phone and instant messaging use, together with a demonstrated comfort level with such mediums, text messaging via mobile devices and the use of instant messaging applications can be effectively incorporated into both peer-to-peer and studentfaculty learning experiences. 


\section{Editorial}

An interesting observation can be made about the study by Lauricella and Kay (2013) in the sense that the two technologies that they studied are apparently being overtaken by other messaging tools. The Financial Times reported in April 2013 that mobile text messaging (SMS) had been overtaken by other messaging apps in 2012 (Thomas \& Bradshaw, 2013). A few months earlier, Microsoft had announced that it would be retiring the existing Messenger service in March 2013, and inviting its users to migrate to Skype (Protalinski, 2013). However, this phenomenon - related to the volatility of technology preferences - does not detract from the main findings of the study, namely that learners appear to make informed choices when using different communication channels with peers or teachers. Instant messaging using mobile devices appears to be an integral part of our spectrum of communication channels, and it makes sense to consider messaging in educational settings.

The second paper by Kjetil Nielsen, Gabrielle Hansen and John B. Stav (2013) reports on the use of student response systems in lecture settings. More specifically, the authors investigate those issues that have been reported to have a negative impact on student experience, and as such this paper presents a rather unusual perspective because the positive aspects usually tend to be put in the spotlight. A student response system (SRS) can be described as an electronic voting system that presents students with a multiple-choice question, often as part of a quiz, to which they will answer with a small handheld device (commonly referred to as a 'clicker'), usually after engaging in peer discussions. The benefits of SRS in lecture situations have been widely reported in the literature, and others have produced best practice guidelines for using SRS in classroom lectures. But as the authors state, focusing primarily on the technology with a belief that the technology will automatically improve lectures, instead of focusing on how students think and learn, is the single most important reason for failure when implementing new technology into education (Mayer 2005), and SRS is no exception. This is why the authors focus their study on those potentially negative aspects that teachers can take into account when planning to use SRS.

The study describes and discusses these aspects based on 3 years of experience (2009-2012) in developing and using an online SRS for modern handheld devices, such as smartphones, at Sør-Trøndelag University College in Norway. The data were collected from students in preparatory engineering courses, aged 22-23 on average, and consist of researcher observations, focused student group interviews and anonymous student surveys. The research observations on the actual use of SRS in the lectures were typically used as a starting point for deeper investigation through the student group interviews. The study identifies and discusses the following aspects that can negatively influence student experience: (1) consistency when using SRS, (2) time usage, (3) preparation, (4) the experience level of the teachers with regard to SRS, (5) teacher commitment and attitudes, (6) teacher explanations, and (7) how students fear that voting results can mislead the teacher. The study concludes by presenting a number of primarily didactic recommendations to teachers.

The study by Nielsen, Hansen and Stav (2013) is timeless in the sense that the recommendations that it offers can be applied to many types of technology used in education. Teachers should have a clear goal and motivation for using the technology in their lectures and be consistent in their use of the technology towards this goal. A lot of attention should be given to preparing the use of the tool with respect to methodology, software and quizzes. Lack of preparation can cause unnecessary disruption but can also give the impression of lacking teacher motivation and 
commitment. Activating students to be more interactive in class implies intensive feedback on the part of the teacher, while teachers should at the same time be careful in interpreting the results of the voting, as there are many factors that can influence students' choices.

Whereas the first two papers in this issue focus on the use of technology by students, the following two papers discuss the use of technology by teachers and staff. Bex Lewis and David Rush (2013) focus on the potential of microblogging for professional development of academic staff. In recent years the phenomenon of personal learning networks has gathered some interest as a tool for professional development. This case study describes a period of 8 months in which one of the authors investigates the potential of using Twitter to increase professional contacts within the framework of a community of practice $(\mathrm{CoP})$. This CoP consisted of innovative educators and support staff in academic institutions and centred around the topic 'knowledge and experience of social media for educational purposes'. These exploring individuals can be regarded as 'digital stewards' within their institutions, who act - formally or informally - as champions of new practices. A digital steward wishing to interact with other digital stewards can join existing networks based on online forums and wikis. Alternatively, by joining social media networks, he/she can try to create a personal network of practice. That is the approach reported here-to target those with similar interests who are using a particular social media system.

The research methodology employed was a narrative case study based on the professional practice of one of the authors (BL). This author's role as a digital steward was to support innovative uses of information technology for teaching in a small university. The author operated independently and had few collaborators within the university. Consequently, as she developed a social media presence, she used it to make contact with similarly placed digital stewards in other universities. The main research issue was whether using Twitter in this way could result in a network of practice of utility in her work as a digital steward. Several types of data were collected and analysed. These included the structure of the network arising from the links formed with others by microblogging, the similarity of stated interests between the academic and others in the network, and the contents of postings such as their external references. It was found that a personal network had been established, with some of the characteristics of a CoP. The activity demonstrated the utility of social media in supporting the professional development of academic staff using technology.

A parallel can be drawn between this paper and the paper by Nielsen and colleagues (2013), in the sense that similar recommendations apply. Professionals wishing to develop a personal learning network need to be clear about their motivation, set a goal for their network, and build it accordingly by finding people with similar interests. The study shows that it takes time and consistent effort to build and maintain such a network of digital stewards, but that through time, a cohesive core network - consisting of overlapping cliques - can be established.

The paper by Thomas Cochrane and Vickel Narayan (2013) extends some of the findings of the previous paper. It evaluates a CoP model for teacher professional development that not only intended to raise awareness about mobile Web 2.0 technologies for teaching but specifically aimed at changing teachers' pedagogical conceptions. The authors developed and taught a professional development course on Social Learning Technologies (SLT) for lecturers in New Zealand's largest polytechnic. In line with the institution's strategy to offer students a 'Living 


\section{Editorial}

curriculum', the course was redeveloped from a teacher-directed training course to a more participative professional development effort. One of the goals of the SLT course was to help the lecturers become expert teachers who move from teacherdirected pedagogy to facilitators of student-determined learning, or heutagogy. The redesigned SLT course focused on modelling the use of mobile Web 2.0 tools as a catalyst for pedagogical transformation, leading to the participants developing their own theory and experience-informed teaching and learning framework. The SLT course ran over the period of a semester, with six 3-hour-long face-to-face sessions, both in 2010 and 2011. The course was designed as an intentional CoP consisting of a small group of participants and two researchers-lecturers.

A participatory action research methodology was used for evaluating the impact of the redesigned SLT course. The research participants included all of the members of the CoP who were involved with the SLT course: the researchers as the lecturers of the SLT course and the course students. Data consisted of: (a) beginning-of-course surveys of lecturers and students to establish current practice, expertise and experience; (b) post-course surveys and focus group surveys to measure the impact of the mobile Web 2.0 environment and identify emergent themes; and (c) lecturer and student reflections via their own blogs and e-portfolios throughout the course. In analysing the qualitative data, the two researchers read through all of the student blog posts and peer comments, viewed the student video reflections and interviewed every student at the end of the course. These multiple qualitative data sources allowed triangulated identification of emergent themes. While the number of participants in the two SLT course iterations was small, the SLT course demonstrates the transformative impact of a CoP model of lecturer professional development. Through a scaffolding approach, the SLT course itself moved from a teacher-directed intentional $\mathrm{CoP}$ to a student-directed community that continues to exist after the end of the course. The 2010 and 2011 course graduates have now become technology stewards within their own departments and institutions, effectively drawing in their peers from the periphery of the SLT CoP and forming spin-off CoPs within their own departments and institutions. Towards the end of the paper, the authors present a practice-oriented mobile social media framework for pedagogical transformation that is scaffolded by a $\mathrm{CoP}$ and utilises the unique affordances of mobile social media.

Whereas Bex \& Rush (2013) argued for the value of social media to establish learning communities across institutions, this paper makes a strong case for the power of a $\mathrm{CoP}$ approach for professional development within an institution. Whereas the Bex \& Rush (2013) study illustrates that their informal and personal approach leads to new knowledge, insights and the establishment of persistent learning networks, it can be argued that the more intensive and semi-formal context and approach in Cochrane \& Narayan (2013) not only achieved new knowledge, insights and the establishment of new learning networks, but can also lead to transformation of technological and pedagogical practice. It would be interesting to find out whether this transformation was sustained throughout the participants' teaching practice in later years.

Whereas the first four papers in this issue dealt with examples of the usage of mobile and Web 2.0 in real-life learning situations, the final paper takes a theoretical perspective. Fang Zhao and Linzi Kemp (2013) develop a testable theoretical model for Web 2.0-based workplace learning. Instead of taking a technological or pedagogical point of view, this paper looks at Web 2.0-based workplace learning 
mainly from social and organisational points of view. The paper extends the perspective from personal learning and professional development to organisational learning and development through the use of Web 2.0 technologies. As Bex and Rush (2013) and Cochrane and Narayan (2013) have clearly shown, there is potential for Web 2.0-based workplace learning to enhance organisational learning and development. However, Zhao and Kemp (2013) find that little systematic research has been published that explores how individual, social and organisational factors may influence Web 2.0-based workplace learning. On the basis of a selective theory review, the authors develop a testable theoretical model for further empirical study, drawing on theories of: (1) social exchange, (2) social capital, (3) communities of practice and (4) organisational support. On the basis of these theories, the authors build a theoretical model and provide suggestions for operationalizing dependent and independent variables to allow empirical testing of the model through a quantitative questionnaire survey either online or by mail.

Interestingly, the model stipulates that communities of practice become crucial mediators through which individual and social factors may have an impact on the process and outcome of Web 2.0-based workplace learning. In other words, the authors hypothesise that a $\mathrm{CoP}$ is so crucial to the hypothesised causalities between individual and social factors as independent variables, and Web 2.0-based workplace learning as a dependent variable that without it, the hypothesised causalities will not exist. It will be interesting to empirically test this model, in order to provide quantitative support for the importance of CoPs, as a complement to the qualitative support that has been reported by other researchers, such as Bex and Rush (2013) and Cochrane and Narayan (2013) in this issue.

How to answer the question in the title? Can we engage learners through Web 2.0 and mobile devices? I think the answer could be: "Yes, but ...". The authors in this issue have shown that focus should be on pedagogy and didactics, on careful goal setting, preparation and reflection, and on the degree to which the learning technology fits with the learning goals that are to be achieved. The potential is there, but so are the risks.

\section{References}

Cochrane, T. \& Narayan, V. (2013) 'Redesigning professional development: reconceptualising teaching using social learning technologies', Research in Learning Technology, vol. 21. DOI: 10.3402/rlt.v21i0.19226.

Lauricella, S. \& Kay, R. (2013) 'Exploring the use of text and instant messaging in higher education classrooms', Research in Learning Technology, vol. 21. DOI: 10.3402/rlt.v21i0. 19061.

Lewis, B. \& Rush, D. (2013) 'Experience of developing Twitter-based communities of practice in higher education', Research in Learning Technology, vol. 21. DOI: 10.3402/rlt.v21i0. 18598.

Mayer, R. (2005) The Cambridge Handbook of Multimedia Learning, Cambridge University Press, Cambridge.

Nielsen, K., Hansen, G. \& Stav, J. (2013) 'Teaching with student response systems (SRS): teacher-centric aspects that can negatively affect students' experience of using SRS', Research in Learning Technology, vol. 21. DOI: 10.3402/rlt.v21i0.18989.

Protalinski, E. (2013) 'Microsoft confirms Messenger will be retired and users migrated to Skype on March 15', The Next Web, [online] Available at: http://thenextweb.com/ microsoft/2013/01/09/microsoft-emails-messenger-users-to-let-them-know-the-service-isretiring-on-march-15-and-to-upgrade-to-skype/ 


\section{Editorial}

Thomas, D. \& Bradshaw, T. (2013) 'Rapid rise of chat apps slims texting cash cow for mobile groups', The Financial Times, [online] Available at: http://www.ft.com/cms/s/0/226ef82eaed3-11e2-bdfd-00144feabdc0.html\#axzz2g6bvtwTC

Zhao, F. \& Kemp, L. (2013) 'Exploring individual, social and organisational effects on Web 2.0-based workplace learning: a research agenda for a systematic approach', Research in Learning Technology, vol. 21. DOI: 10.3402/rlt.v21i0.19089.

Steven Verjans Open Universiteit

NL 